\title{
Paisagens enclausuradas: imagens resultantes do contágio de meios analógicos e digitais
}

\author{
LURDI BLAUTH
}

Lurdi Blath é artista plástica, professora, pesquisadora. Doutora em Artes Visuais, PPGAV, UFRGS/RS. Estágio Doutorado Université Pantheon-Sorbonne, Paris I, França. Atua nos cursos de Artes Visuais e no PPG de Processos e Manifestações Culturais; lider da pesquisa Imagem e Texto: inscrições e grafias em poéticas contemporâneas, Universidade Feevale Novo Hamburgo/RS, com apoio do CNPQ. Realiza exposições individuais e coletivas, nacionais e internacionais. E-mail: lurdib@feevale.br / lurdiblauth@gmail.com 
- RESUMO

Este artigo aborda a produção de imagens na área da gravura, oriundas do contágio de procedimentos analógicos e digitais. As imagens resultantes desses contatos híbridos configuram uma outra visualidade e, no trânsito entre os diferentes meios, o acaso, a perda e a permanência são incorporados ao meu processo de criação artístico. O estudo aborda questões relacionadas à natureza de imagens cuja origem são fotografias digitais, que são gravadas em matrizes de cobre - reconfigurando-se na materialidade de gravuras - e impressas tradicionalmente, nas quais, depois dessa etapa, são realizadas interferências com processos pictóricos.

\section{- PALAVRAS-CHAVE}

Imagem, gravura, fotografia, impressão.

\section{- ABSTRACT}

The present article approaches the production of images, in the engraving area, originated by analog and digital contamination processes. The images that result from such hybrid contact configure a different visuality and, the transit between the different means, chance, losses and permanences are incorporated to my artistic creation process. The study approaches matters related to the nature of images whose origin are digital photographs, that are engraved on copper plates - reconfiguring themselves to the engraving materiality - and printed in the traditional way, in which, after this stage, are made painting interferences.

\section{- KEYWORDS}

Image, engraving, photography, printing.

\section{Introdução}

As imagens na área da gravura atual podem inter-relacionar diferentes dispositivos, desde os meios tradicionais até os meios tecnológicos digitais, impulsionando-me pensar sobre as implicações dessas mudanças e as relações que se estabelecem a partir da interação com novos meios de produção. Essas questões vêm sendo investigadas em minha produção artística, principalmente na gravura, cujas imagens têm sido resultantes desse contágio híbrido entre distintas materialidades e linguagens. As experiências começam com a fotografia digital, que propicia a captura instantânea de inúmeras imagens de objetos, marcas, paisagens, entre outros elementos que o olhar vai detectando no caminho do dia a dia. Surgem inúmeras imagens e, aí, se impõe uma questão: o que fazer com todas essas imagens? Num primeiro momento, são colocadas em arquivos virtuais separadas por assunto, e que poderão ser utilizadas em futuras configurações e outras materialidades. 
Para pensar sobre transformações no estatuto da imagem e o que ocorre no processo de transposição de uma linguagem para outra, em seus contágios híbridos, tomo como referência, neste estudo, os conceitos de imagem, fotografia, gravura e as possibilidades de reprodução. Em termos gerais, a cada nova invenção tecnológica, novos materiais e experiências são articuladas pelos artistas e, consequentemente, nesse diálogo da arte com a ciência, ocorrem mudanças nas práticas artísticas. Com a invenção da fotografia, intensifica-se a aproximação entre a arte e a tecnologia, propiciando a liberação da representação tradicional de espaço e a realização de novas experiências. Embora a fotografia tenha assumido a função de obter imagens do real, também instiga os artistas para a criação de imagens com a manipulação de seus processos mecânicos e químicos. Desse modo, “a arte, [...], envolveu-se com toda a sua poética nas mudanças ocorridas no século $X X$, ora com reações viscerais diante do mundo em transformação, subvertendo a ordem, ora como participante do objeto da própria transformação" (VENTURELLI, 2004, p.13). No momento atual, "estamos na idade de instantâneo e do imediatismo" (IDEM, p. 13), assim, configuram-se outras relações de espaço e tempo entre o real e o virtual, em suas infinitas possibilidades de interação com as tecnologias digitais, cujas imagens duplicam nossa capacidade de ver o mundo e de operar a própria realidade.

Contudo, ao pensarmos em uma imagem, geralmente associamos uma forma com alguma semelhança ou representação de um objeto, ou uma situação real. Nesse aspecto, para Jocelyne Alloucherie (2012), a imagem pode ser ou não percebida como substituta ou mesmo ter um certo grau de fidelidade com o real. Para a autora, a imagem nos "inscreve numa distância mental". Nesse sentido, é que podemos, talvez, nos aproximar de sua verdadeira natureza.

Ela nos desloca com a ilusão de uma presença fictícia; ela nos exclui de um imediatismo temporal. Toda imagem é indecifrável, vaga, neste duplo sentido, nesta natureza contraditória: ela nos envolve e afasta; ela age na inclusão e exclusão. Ela é a própria dualidade. Certos meios de representá-la acentuam essa particularidade. (ALLOUCHERIE, 2012, p.9).

Por outro lado, a dualidade da imagem evoca uma semelhança, porém, não necessariamente reproduz uma cópia fiel, apenas o suficiente para tomar o lugar do objeto. Ao operar distintos meios, também produz uma distância, uma lacuna, uma dessemelhança (RANCIÈRE, 2012, p. 15). Para o autor, a arte é resultante de um jogo 
de operações que altera a semelhança, por exemplo, o fato de uma série de pinceladas poder configurar a representação de um retrato. Contudo, “a imagem não é uma exclusividade do visível. Há um visível que não produz imagem, há imagens que estão todas em palavras". A imagem possui uma relação não apenas dupla, mas tripla, denominada de arquissemelhança, que é a semelhança originária. Isto é, "a semelhança que não fornece a réplica de uma realidade, mas o testemunho imediato de um outro lugar, de onde ela provém". (IDEM, p. 17).

Nessa perspectiva, entendemos que, esse outro lugar situa-se na brecha, naquilo que emana para além das aparências das coisas, algo que descola da superfície para alojar-se entre o visível e o dizível. Se a fotografia captura algo da realidade, ou registra o fragmento de um instante, - $o$ isso-foi de Barthes, porém, a imagem, ao ser inserida no computador, já não reside em lugar nenhum, nem no tempo, assume uma outra temporalidade e dimensionalidade. A imagem pode ser alterada infinitamente é, nesse sentido que, a produção de semelhanças em relação ao referente real se modifica. De certa maneira, a imagem técnica contribui para a 'desrealização' do mundo visível, o que nos leva a pensar a imagem fora da sua função indicial e dos limites da mimese. A intervenção digital no campo da fotografia também incrementa os recursos da fotografia analógica, bem como produz mudanças sobre a crença na objetividade da fotografia, como reprodução do real. (MACHADO, s/d).

No contato, sobretudo, das interfaces dos meios analógico e digitais, há uma certa desrealização da imagem referente, bem como colocam-se as possibilidades híbridas entre representação e simulação. "Hibridação [...] entre o pensamento tecno-científico, formalizável, automatizável, e o pensamento figurativo criador, cujo imaginário nutre-se num universo simbólico da natureza diversa". (COUCHT, 1999, p. 47) Ou seja, trata-se, no campo da arte de, "transformar as certezas das ciências em incertezas das sensibilidades". (IDEM, p.46). Se por um lado há um certo controle do mundo das imagens pelas tecnologias numéricas, de outro, a potencialidade dos meios digitais permite que a imagem seja reproduzida pela repetição, e qualquer suporte pode acolher a sua amplificação. Para Edmund Couchot, "a ordem numérica, torna possível uma hibridação quase orgânica das formas visuais e sonoras, do texto 
e da imagem, das artes, das linguagens, dos saberes instrumentais, dos modos de pensamento e de percepção". (IDEM, p.47).

Nesta perspectiva, as imagens técnicas, ao mesmo tempo em que são ampliadas as suas possibilidades de reprodução, igualmente a estrutura da mediação influi sobre a ambiguidade do gesto produtor de imagens técnicas e do gesto produtor de imagens tradicionais. (FLUSSER, 2008). O autor, em seus estudos, trata de elementos que estruturam a imagem enquanto "superfícies que pretendem representar algo", (FLUSSER, 2002, p.7), assim como podemos pensar em imagens históricas, em imagens técnicas. Entende que "as imagens tradicionais imaginam o mundo e as imagens técnicas imaginam textos que concebem imagens que imaginam o mundo". (IDEM, p.13). As imagens técnicas são produtos indiretos dos textos, diferenciando-se das imagens tradicionais que são mediadas pelo gesto humano, como a pintura, o desenho, a gravura, etc.

A criação de imagens oriundas de tecnologias digitais, portanto, envolve especificidades, cujos códigos se diferenciam de uma imagem produzida por meios tradicionais. Em princípio, as qualidades de uma gravura em metal, por exemplo, implicam na manualidade física de instrumentos que revelam a unicidade e a irrepetibilidade de um gesto presente nos suportes empregados, na materialidade das texturas, dos relevos, dos sulcos e da tridimensionalidade da matriz. Essas qualidades matéricas não existem na tecnologia digital, pois a sua base é numérica, isto é, imaterial. Não tem relação com o objeto concreto, por não apresentam dimensões em termos de texturas e relevos. Ou seja, todos os pontos são reduzidos a pixels iguais e "a impressão final não faz distinção entre a origem da imagem, ela simplesmente reflete a imagem digital”. (JURGENS, 2009, apud: COLDWELL, 2012, p. 18).

A aproximação de meios digitais e tradicionais, em específico, a calcografia gravura em metal, tem provocado mudanças em meu processo de criação artística. São outros questionamentos suscitados no modo de produção, envolvendo em seus princípios, qualidades e diferenças. Os registros fotográficos que realizo, de uma paisagem ou de um objeto real, por exemplo, transformam-se em imagens, isto é, em superfícies traduzidas por elementos mínimos, no momento em que são inseridas no computador. Considero essas imagens como anotações guardadas em arquivos digitais 
que podem ser acionadas para adquirir outra materialidade, além de me propiciar transformações quase infinitas, ao contrário dos meios convencionais.

No entanto, no momento em que a imagem, depois de manipulada, é impressa e novamente transferida para uma matriz de cobre, e gravada por meio de ácidos, de certa maneira, nesse processo, adquire uma certa permanência através da forma e do volume, retornando à tridimensionalidade através do suporte da matriz e do papel. Pergunta-se: afinal o que permanece da imagem original? Pode-se dizer que, as imagens têm alguma analogia com o conteúdo ao qual estão vinculadas e com as relações que estabelecem em cada processo. Entre acasos e perdas, entre a linguagem e números, num certo sentido, guardam algo que permanece da natureza segmentada da imagem.
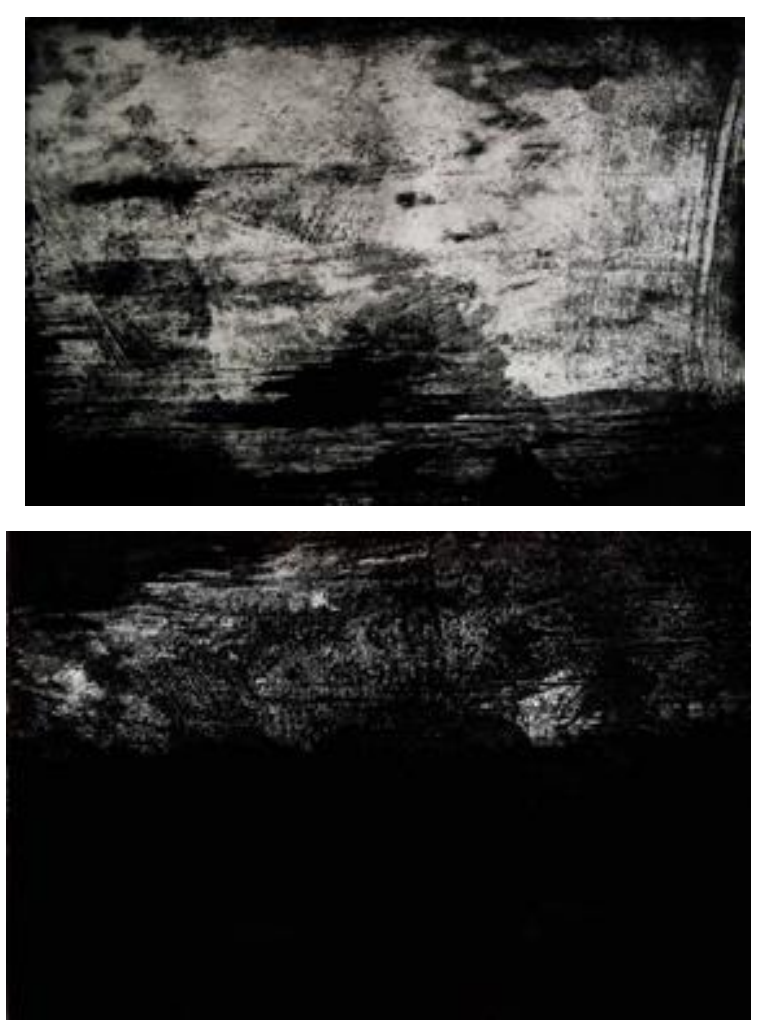

Figuras 1 e 2 - Lurdi Blauth. Passagem IX e X, água tinta, impressão digital sobre canvas hannemühle, $60 \times 100 \mathrm{~cm} .2013$. Fotografia do autor.

Na série Passagens entre paisagens (2013), por exemplo, há uma interlocução entre os meios analógicos e digitais (Figuras 1 e 2). A imagem é inicialmente capturada pela fotografia digital, inserida no computador, manipulada e impressa numa impressora de jato de tinta. Essa imagem planificada sobre o papel, é novamente 
transferida para uma matriz de cobre, a qual é gravada por corrosão de ácido. Nessa transposição, ocorrem modificações em relação à imagem, porém, revelam-se vestígios da imagem primeira, que revelam, talvez, a arquissemelhança, algo de um outro lugar, preconizada por Rancière. Os elementos de fragmentos mínimos da natureza constituem-se como permanências por meio da presença matérica, uma possível aderência à realidade visível.

Nesse sentido, as múltiplas possibilidades imateriais e controladas da tecnologia digital e a interação com a materialidade física da gravura, oportunizam a formação de novas imagens. Numa etapa posterior da impressão tradicional, essas gravuras são novamente digitalizadas para trabalhar a ampliação de suas dimensões originais. As imagens-matrizes são duplicadas e traduzidas por códigos numéricos e impressas por processos mecânicos sobre canvas, configurando-se como um múltiplo. Ou seja, a imagem, ao ser transformada em um arquivo digital, tem a potencialidade de ser multiplicada infinitamente.

Os procedimentos analógicos e digitais, portanto, dialogam e esgarçam as fronteiras das delimitações conceituais, propiciando pensarmos sobre processos de multiplicação de imagens a partir do sistema de reprodução, que podem ter os seus significados ampliados a partir do único. Sob esse aspecto, também se problematiza a ideia da dimensão limitada de matrizes-imagens dos processos tradicionais, propondose a busca dessa outra potencialidade de duplicação e multiplicação da imagemmatriz. E, talvez, nesse sentido, reside a temporalidade da imagem, entre o desejo de permanência e a impermanência em suas possibilidades de gerar outras significações.

\section{Paisagens enclausuradas: imagens resultantes do contágio de meios analógicos e digitais}

Os trabalhos que compõem a série Paisagens Enclausuradas são um desdobramento de trabalhos anteriores, denominada de série Cárceres, realizadas a partir de fotografias de ex-prisões, como o Porão do Paço Municipal de Porto Alegre, RS, o ex-cárcere de Miguelete, Montevideo, UY e Mont Saint-Michel, FR. Esses locais de confinamento e de reclusão, embora redimensionados como espaços de interação pública, ainda suscitam indagações sobre essa realidade de aprisionamentos e vigilância (Figuras 3 e 4) 


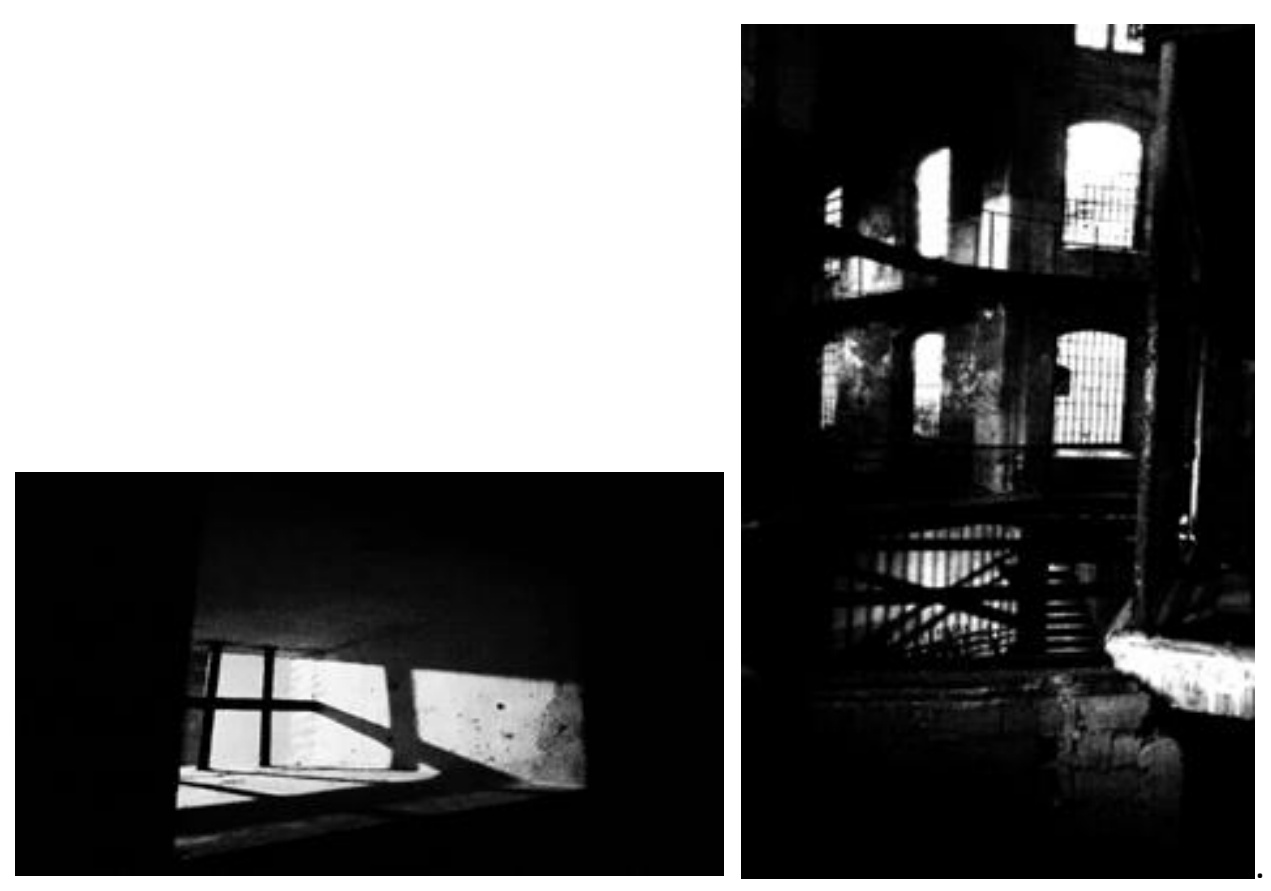

Figuras 3 e 4 - Lurdi Blauth. Cárcere I e III, fotografia digital, impressão s/canvas, 60x100cm, $100 \times 60 \mathrm{~cm}, 2013$. Fotografia do autor.

Para a exposição Inter-dito, continuo redimensionando essas questões por meio da utilização de imagens oriundas dos meus arquivos digitais dos locais mencionados, bem como a inclusão de detalhes de estruturas que remetem à ideia de limites e impedimentos de ir e vir, entre o interior e o exterior. As imagens desses trabalhos são constituídas a partir de desdobramentos vinculados a procedimentos que envolvem a transferência, gravação de matriz e impressão. A fotografia, aqui, é novamente incorporada como um dispositivo indiciário deflagrador de registro inicial, bem como a introdução de meios digitais pelas possibilidades de manipulação e a transformação em contrastes de pretos e brancos, buscando uma aproximação aos processos da gravura. A partir do tratamento das imagens pela interação híbrida entre diferentes meios, são introduzidos procedimentos pictóricos, como a encáustica sobre as gravuras impressas sobre papel, e ainda a inserção de imagens transferidas sobre placas de alumínio em dois trabalhos. (Figuras 5 e 6). 

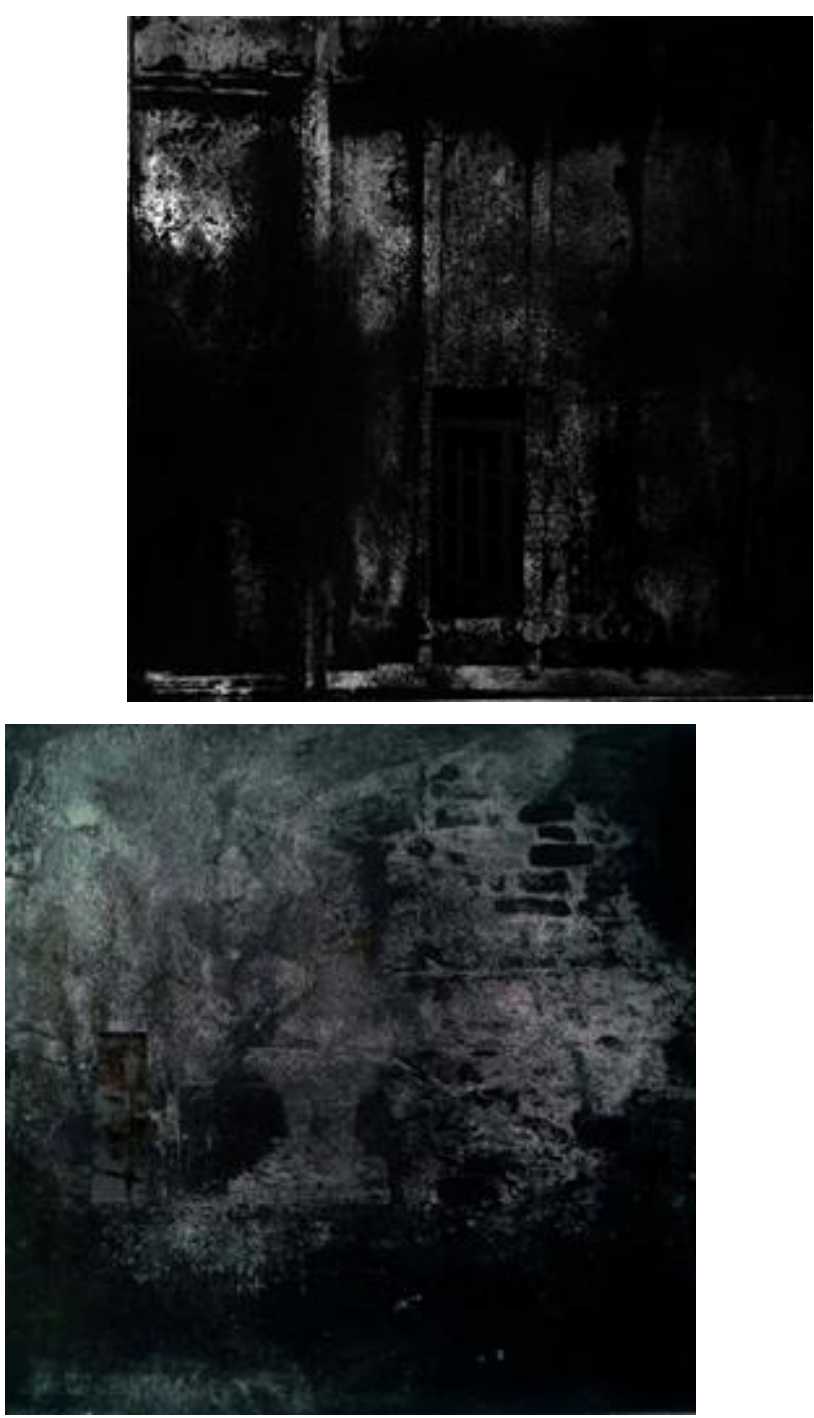

Figuras 5 e 6 - Lurdi Blauth. PE II - PE III, água tinta - impressão s/hannemühle, 40x40cm, 2015. Fotografia do autor.

Por outro lado, o meu processo de criação de imagens sobre matrizes de cobre configura o envolvimento de um tempo de espera paciente, desde a gravação no ácido, a entintagem e a impressão cuidadosa sobre o papel úmido. É um processo que exige a interação e a entrega em todas as etapas dessa linguagem artística, cujos resultados me instigam a pensar sobre as flutuações dialéticas dos deslocamentos provocados pelas transposições entre o gravado e o não gravado, entre o controlado e não controlado. Diante da reação do ácido associado a ação do tempo, procuro problematizar a questão dos elementos e vestígios de imagens que permanecem nos sulcos gravados das matrizes, e também relacionar, através dessas imagens, para uma realidade em clausura. 
A proposição de pensarmos sobre a relação da palavra-imagem inter-dito, vem ao encontro de fotografias realizadas de ex-prisões, armazenadas em arquivos digitais, desde 2003. Para tanto, foram trabalhadas um conjunto de imagens denominadas de Paisagens Enclausuradas com o intuito de propor analogias com referências indiciais de uma realidade onde o tempo foi colocado em suspensão. Embora, esses lugares de confinamento estejam transformados em espaços de interação pública, ainda provocam indagações sobre esses espaços ficcionais.

Sobre estes locais de encarceramento, mencionamos as reflexões de Foucault sobre o princípio de panóptipo de Bentham, como modelo de sociedade de disciplina e ordenação das multiplicidades humanas, possibilitando o vigiar constante e o reconhecer imediato. O sujeito é "visto, mas não vê; objeto de uma informação, nunca sujeito numa comunicação". (FOUCAULT, 1999, p.166). O que antes, nas masmorras tinham a função de encarcerar, ocultar e privar da luz do dia, no modelo panóptico é conservado apenas a função de confinar a liberdade. "A plena luz e o olhar de um vigia captam melhor que a sombra, que finalmente protegia. A visibilidade é uma armadilha". (IDEM, 166). A constante visibilidade assegurava o funcionamento de uma situação de poder e de controle. As relações entre os campos de visibilidade, cerceamentos e limitações de espaços prisionais em as referências de controle, atualmente se modificaram, são outras problemáticas, que não pretendo enfocar no meu trabalho poético, embora estejamos convivendo com a essas situações de outras formas de vigilância.

Os trabalhos que ora desenvolvo foram desencadeados a partir do acesso e de observações nestes espaços que foram transformados em locais públicos, mas que ainda mantém vestígios arquiteturais muito densos, me sensibilizaram para pensar sobre relações de submissões instituídos pelo poder, em suas limitações e cerceamentos entre vigiar e punir. Desse modo, no conjunto desses trabalhos encontramos alguns registros que traduzem marcas de grades, de fechaduras, de sombras entre aberturas e cruzamentos de sentidos em suas possíveis ressignificações poéticas (Figuras 7 e 8 ). 
Nos trabalhos abaixo, por exemplo, aproximo dois locais de países distintos, com o intuito de colocarmos em tensão operações conceituais que hibridizam procedimentos adotados. A fotografia como dispositivo deflagrador da imagem, a calcografia, que produz sulcos e marcas nas superfícies das matrizes, a impressão sobre papel e a materialidade pictórico da encáustica, reconfigurando o contato de uma fisicalidade. A primeira imagem refere-se ao Porão do Paço Municipal, na qual foi feito um recorte como uma janela que remete para uma segunda imagem, que é um detalhe da ex-prisão de Miguelete. (Figuras 9 e 10).
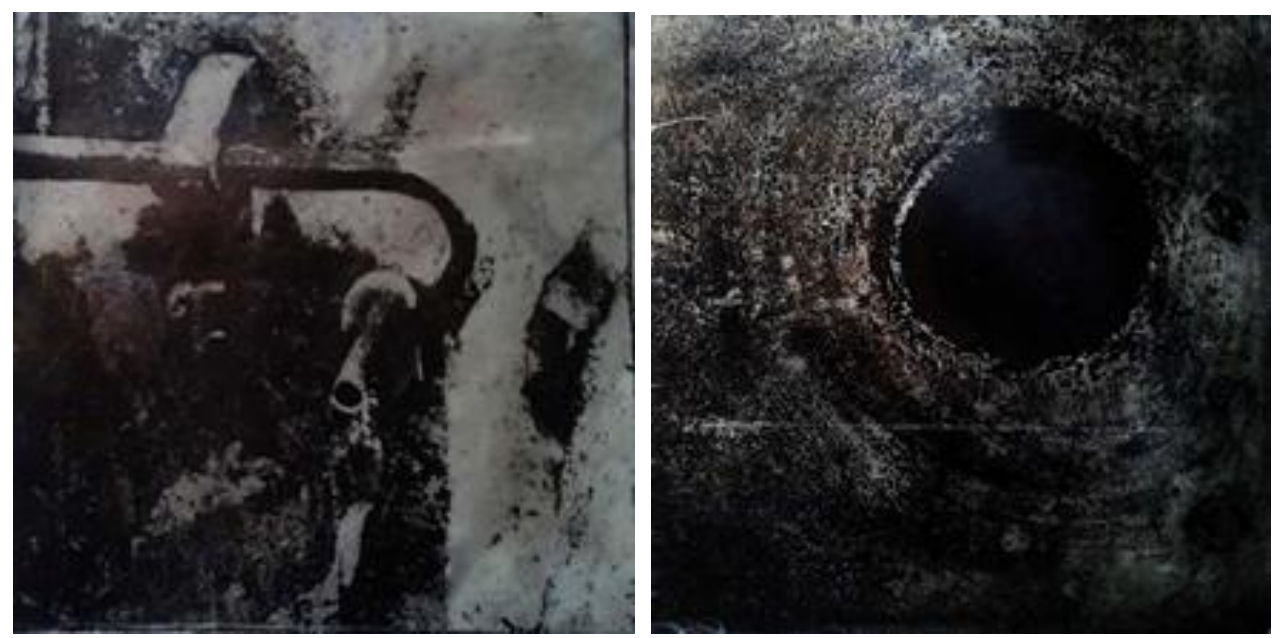

Figuras 7 e 8 - Lurdi Blauth. PE VI - PE VII, água tinta e encáustica - impressão s/hannemühle, $20 \times 20 \mathrm{~cm}, 2015$. Fotografia do autor.

Essas imagens, num certo sentido, colocam em suspensão o olhar que se aloja no anteparo da imagem e remete à ideia de clausura e limites, uma certa finitude. A inserção de uma fenda produzida por um recorte e a justaposição de uma outra imagem, instauram uma certa claudicação entre o dentro e o fora. Nesse espaço, se interpõe a possibilidade de vislumbrarmos uma abertura, isto é, a possibilidade de atravessamento, porém o que encontramos é um impedimento, uma nova interdição.

\section{Breves considerações}

As imagens da série Paisagens Enclausuradas, portanto, são constituídas pelo cruzamento dialético entre o visível e o invisível, entre a perda e a permanência. 
Portanto, a produção dessa série de trabalhos poéticos faz referências à espaços de clausuras e reclusões, bem como a certos detalhes que fazem parte de estruturas que evocam a presença do cerceamento da perda e da liberdade de ir e vir. O que permanece, é uma realidade cada vez mais vigiada por meio de monitoramentos invisíveis e imperceptíveis, em seus inúmeros dispositivos presentes nos dias atuais. A visibilidade é também uma armadilha!
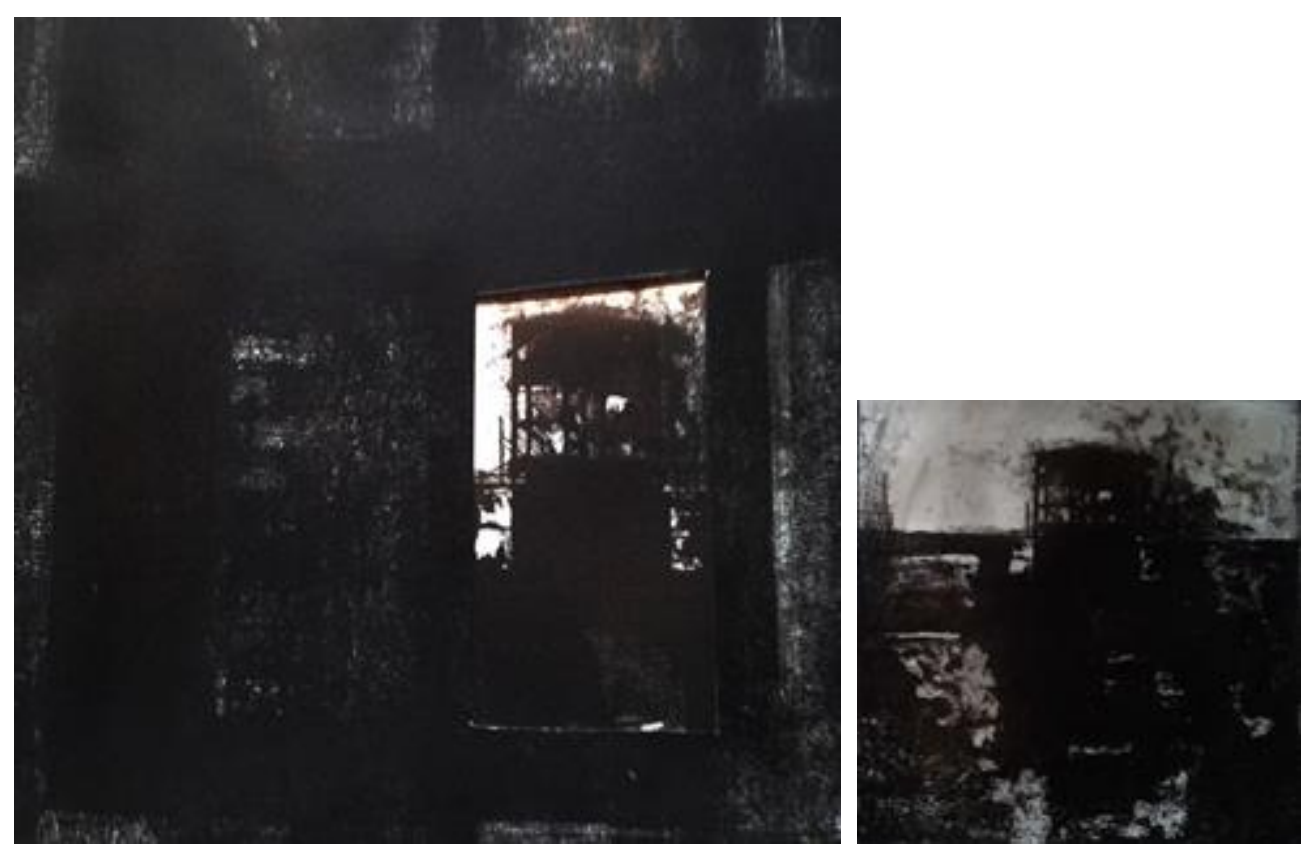

Figuras 9 e 10 - Lurdi Blauth. PE I - PE V , água tinta e encáustica - impressão s/hannemühle, $40 \times 40 \mathrm{~cm}, 20 \times 20 \mathrm{~cm}, 2015$. Fotografia do autor.

\section{Referências}

ALLOUCHERIE, J. A permeabilidade das fronteiras. Revista Porto Arte - revista de Artes Visuais. Porto Alegre: UFRGS, 2012.

COUCHOT, E. Da representação à simulação: evolução das técnicas e das artes da figuração. IN: PARENTE, A. (ORG.). Imagem-máquina - a era das tecnologias do virtual. 3ạ ed. Rio de Janeiro: Editora 34, 1999.

FLUSSER, V. Filosofia da caixa preta - ensaios para uma futura filosofia da fotografia. Rio de Janeiro: Relume Dumará, 2002.

O universo das imagens técnicas. São Paulo: Annablume, 2008.

FOUCAULT, M. Vigiar e punir: nascimento da prisão; tradução de Raquel Ramalhete. 20 a edição. Petrópolis, Vozes, 1999. IN: 
https://comunicacaodasartesdocorpo.files.wordpress.com/2013/11/foucault-michel-vigiar-e-

punir.pdf Acesso em: 20/06/2015

JURGENS, M. C. 2009. APUD: COLDWELL, Paul. Gravura - novas e velhas tecnologias - uma conversa. Revista Porto Arte - revista de Artes Visuais. Porto Alegre: UFRGS, 2012.

MACHADO, A. Fotografia em mutação. IN: http://www.uel.br/pos/fotografia/wpcontent/uploads/downs-uteis-fotografia-em-mutacao.pdf. Acesso em: 3/8/2013

RANCIÈRE, J. O destino das imagens. Rio de Janeiro: Contraponto, 2012.

VENTURELLI, S. Arte: espaço, tempo, imagem. Brasília: Editora da Universidade de Brasília, 2004. 